\title{
Efficacy evaluation of serum galectin-3 in hypertension complicated with diastolic dysfunction
}

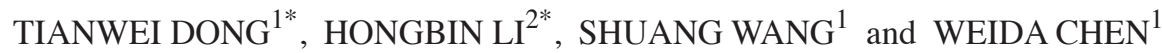 \\ Departments of ${ }^{1}$ Cardiovascular Medicine and ${ }^{2}$ Neurosurgery, The First Affiliated Hospital of Jiamusi University, \\ Jiamusi, Heilongjiang 154002, P.R. China
}

Received March 15, 2019; Accepted July 15, 2019

DOI: $10.3892 /$ etm.2019.8215

\begin{abstract}
Serum galectin-3 (Gal-3) in patients with hypertension complicated with diastolic dysfunction and its predictive value for efficacy were investigated. One hundred patients with hypertension complicated with diastolic dysfunction admitted to the First Affiliated Hospital of Jiamusi University from June 2017 to December 2018 were enrolled as group A, symptomatically treated with conventional drugs. Further 80 individuals undergoing physical examination during the same period were enrolled as group B. Patients in the two groups were subjected to echocardiography to observe mitral valve early peak flow velocity (EPFV), atrial peak flow velocity (APFV), maximum flow velocity ratio of early to atrial diastole (EPFV/APFV) and peak mitral annulus velocity (E/E'). Enzyme-linked immunosorbent assay (ELISA) was used to detect serum Gal-3 concentration. According to efficacy after treatment, patients in group A were divided into the effective group (71 patients) and the invalid group (29 patients). Gal-3 concentration in group A was significantly higher than that in group B $(\mathrm{P}<0.05)$. After treatment, the concentration in group A was significantly lower than that before treatment $(\mathrm{P}<0.05)$, but significantly higher than that in group $\mathrm{B}(\mathrm{P}<0.05)$. Gal-3 concentration was significantly higher in patients with cardiac function grades II, III and IV than that in patients with grade I $(\mathrm{P}<0.05)$. According to Spearman's test, Gal-3 concentration was positively correlated with cardiac function grading $(\mathrm{r}=0.569, \mathrm{P}<0.001)$. Compared with before treatment in group A, patients after treatment had significantly higher EPFV and EPFV/APFV $(\mathrm{P}<0.05)$, but significantly lower $\mathrm{APFV}$ and $\mathrm{E} / \mathrm{E}^{\prime}(\mathrm{P}<0.05)$. Before treatment, Gal-3 concentration in the effective group was significantly
\end{abstract}

Correspondence to: Dr Weida Chen, Department of Cardiovascular Medicine, The First Affiliated Hospital of Jiamusi University, 348 Dexiang Street, Jiamusi, Heilongjiang 154002, P.R. China E-mail: d6y7ny@163.com; dada163437@163.com

*Contributed equally

Key words: hypertension complicated with diastolic dysfunction, galectin-3, clinical efficacy, predictive value lower than that in the invalid group $(\mathrm{P}<0.05)$. According to the receiver operating characteristic (ROC) curve, the area under curve (AUC) of Gal-3 concentration for evaluating efficacy was 0.792 , the sensitivity was $73.24 \%$, and the specificity was $79.31 \%$. In conclusion, Gal-3 may be involved in the development and progression of hypertension complicated with diastolic dysfunction. Its concentration increases with the rise of cardiac function grading but significantly decreases after treatment. Therefore, Gal-3 concentration before treatment can be used as a potential predictor of efficacy.

\section{Introduction}

Hypertension as a clinically common disease is divided into primary and secondary hypertension, of which the former is more common (1). Hypertension endangers the health of adults and children, and causes multi-organ diseases, especially diseases in the cardiovascular system. The disease worsens with time if the patients are not treated properly (2). Hypertension usually leads to heart failure, left ventricular hypertrophy and other complications, which cause significant heart injury, affecting left ventricular diastolic function and result in cardiac dysfunction (3). The progression of hypertensive heart disease includes myocardial fibrosis and changes in left ventricular geometry, without signs and symptoms of heart failure or left ventricular systolic dysfunction before functional changes $(4,5)$. Half of the patients with hypertension have diastolic dysfunction, which has proved closely related to the increasing incidence and morbidity of cardiovascular diseases and the progression of heart failure (6). Patients with diastolic dysfunction have increased year by year with the high incidence of hypertension and its complications (7).

Hypertension is usually treated with angiotensin converting enzyme inhibitor (ACEI), angiotensin II receptor antagonist (ARB), calcium antagonist (CCB) and $\beta$ receptor blockers. These drugs can relieve hypertensive patients' left ventricular diastolic function, clinical signs and symptoms $(5,8,9)$. Galectin-3 (Gal-3), which is a member of the galectin family and a $\beta$-galactoside-binding protein of $30-\mathrm{kDa}$, plays an important role in immune regulation (10). As a pathogenic factor of heart failure, Gal-3 not only causes myocardial inflammation and fibrosis and affects left ventricular systolic function, but also promotes cardiac remodeling, myocardial fibrosis and heart failure (11). 
According to a previous study, Gal-3 is closely related to the development and progression of cardiovascular diseases, expected to be a biomarker for assisting the diagnosis and prognosis of cardiac diseases (12). However, the role of Gal-3 in the development, progression and treatment of hypertension complicated with diastolic dysfunction remains unclear. Therefore, GAL-3 expression in patients with the disease was detected in this study to explore the role of Gal-3 in the development, progression and treatment of the disease.

\section{Patients and methods}

General information. One hundred patients with hypertension complicated with diastolic dysfunction admitted to The First Affiliated Hospital of Jiamusi University (Jiamusi, China) from June 2017 to December 2018 were enrolled as group A. The patients consisted of 53 males and 47 females, aged 46-75 years with an average age of $63.57 \pm 10.38$ years. According to the New York Heart Association (NYHA) Functional Classification (13), there were 20 patients with grade I, 26 patients with grade II, 30 patients with grade III and 24 patients with grade IV in group A. Inclusion criteria for group A: Patients who met the diagnostic criteria for hypertension in the World Health Organization/International Society of Hypertension (WHO/ISH) (14); patients with an E/A value of cardiac color ultrasound $<1$; patients with a diastolic pressure $\geq 90 \mathrm{mmHg}$ or a systolic pressure $\geq 140 \mathrm{mmHg}$. Exclusion criteria: Those with secondary hypertension, coronary heart disease, valvular heart disease, congenital heart disease, cerebrovascular diseases, cardiomyopathy, diabetes, acute pulmonary embolism, connective tissue diseases, nervous system diseases, immune diseases, endocrine and metabolic diseases, malignant tumors or severe hepatorenal damage; those with mental illness and a family history of psychosis; those who had taken diuretic drugs to reduce blood pressure within the past 3 months; those who were not treated according to the doctor's advice. Further 80 individuals undergoing physical examination during the same period served as group B. The subjects in group B consisted of 46 males and 34 females, aged 41-69 years with an average age of $60.69 \pm 10.67$ years. The inclusion criteria were applied to group A, and the subjects in group B were healthy controls.

This study was approved by the Ethics Committee of The First Affiliated Hospital of Jiamusi University. The subjects and their families were informed and signed a fully informed consent form.

Therapeutic methods and efficacy evaluation. Patients in group A were routinely treated, which included smoking cessation, temperance, reduction of sodium intake, weight and fat intake, and increasing of aerobic exercise. Their myocardial function and blood pressure were monitored in real-time. According to conditions, the patients were treated with ACEI, ARB, CCB and $\beta$ receptor blockers for 3 months, with diuresis, potassium excretion and correction of acid-base equilibrium disorders given at the same time. Adverse reactions during the treatment were observed. Grading: Markedly effective: Symptoms and signs disappeared completely, and improvement of cardiac function was grade II. Effective: Symptoms and signs were improved, and improvement of cardiac function was grade I. Invalid: Symptoms, signs and cardiac function had no significant change and even worsened.
Echocardiography. GE Vivid 7 color ultrasonic device (General Electric Company) and M3S probe with $2.5 \mathrm{MHz}$ were used for analysis and measurement by specialist physicians in ultrasonic medicine. Subjects were in supine position breathing calmly, and their ECG was synchronously recorded to obtain the standard two-dimensional images of sections of the heart, and the frequency spectrums of valve orifices and pulmonary vein. Left ventricular diastolic function was determined with respect to mitral valve early peak flow velocity (EPFV), atrial peak flow velocity (APFV), maximum flow velocity ratio of early to atrial diastole (EPFV/APFV) and peak mitral annulus velocity (E/E').

Detection methods. Five milliliters of fasting peripheral blood was extracted, placed in a vacuum tube free of anticoagulant, and centrifuged at $670.8 \mathrm{x} \mathrm{g}$, at $20-25^{\circ} \mathrm{C}$ for $10 \mathrm{~min}$ to separate serum. An Elx-800 microplate reader (BioTek) was used to detect serum Gal-3 concentration, with steps carried out in accordance with the instructions of human Gal-3 enzyme-linked immunosorbent assay (ELISA) kit (Renjie Biotechnology Co., Ltd.). The kit and the sample to be tested were taken out $20 \mathrm{~min}$ in advance to balance with room temperature. Sample wells, standard wells and blank wells were set up. The standard wells were added with $50 \mu \mathrm{l}$ of standard substances with different concentrations, the sample wells were added with $50 \mu$ l of the sample to be tested, nothing was added to the blank wells. The wells were added with $100 \mu \mathrm{l}$ of horseradish peroxidase (HRP)-labeled detection secondary goat anti-human IgG monoclonal antibody (1:250; cat. no. A0201; Beyotime Institute of Biotechnology) (https:// www.beyotime.com/product/A0201.htm), covered with tectorial membranes, and incubated at $37^{\circ} \mathrm{C}$ for $1 \mathrm{~h}$. After that, they were added with $350 \mu \mathrm{l}$ of cleaning solution and allowed to stand for $1 \mathrm{~min}$. The liquid in wells was discarded and the wells were dried with absorbent paper. The wells were washed 5 times. Next, the wells were added with $50 \mu \mathrm{l}$ each of substrates A and $\mathrm{B}$, and incubated at $37^{\circ} \mathrm{C}$ for $15 \mathrm{~min}$ in the dark. Finally, they were added with $50 \mu \mathrm{l}$ of stop solution. The Elx-800 microplate reader was used to detect OD values of wells at $450 \mathrm{~nm}$ within $15 \mathrm{~min}$, in order to calculate Gal-3 concentration.

Statistical analysis. SPSS 20.0 (IBM Corporation) was used to statistically analyze the data, GraphPad Prism 7 (GraphPad Software, Inc.) to plot figures. Enumeration data were expressed as [n (\%)], and Chi-square test was used for comparison of enumeration data between groups. Measurement data were expressed as mean \pm standard deviation (mean \pm SD), and independent samples t-test was used for comparison of measurement data between groups, paired t-test for comparison before and after treatment within groups. Spearman's test was used for correlation analysis. The receiver operating characteristic (ROC) curve was used to plot the diagnostic value of Gal-3 concentration before treatment for efficacy. $\mathrm{P}<0.05$ indicated a statistically significant difference.

\section{Results}

Comparison of general information. There was no significant difference between group A and group B in terms of sex, age, history of smoking, history of drinking, place of residence, educational level, fasting blood glucose (FBG), hemoglobin (Hb), red blood cell (RBC) count, platelet (PLT) 
Table I. Comparison of general information $[\mathrm{n}(\%)]($ mean $\pm \mathrm{SD})$.

\begin{tabular}{|c|c|c|c|c|}
\hline Category & Group A $(n=100)$ & Group B $(n=80)$ & $t / \chi^{2}$ & P-value \\
\hline Sex & & & 0.364 & 0.547 \\
\hline Male & $53(53.00)$ & $46(57.50)$ & & \\
\hline Female & $47(47.00)$ & $34(42.50)$ & & \\
\hline Age (years) & $63.57 \pm 10.38$ & $60.69 \pm 10.67$ & 1.827 & 0.069 \\
\hline History of smoking & & & 0.190 & 0.663 \\
\hline Yes & $57(57.00)$ & $43(53.75)$ & & \\
\hline No & $43(43.00)$ & $37(46.25)$ & & \\
\hline History of drinking & & & 0.251 & 0.616 \\
\hline Yes & $55(55.00)$ & $41(51.25)$ & & \\
\hline No & $45(45.00)$ & $39(48.75)$ & & \\
\hline Place of residence & & & 0.641 & 0.423 \\
\hline City & $67(67.00)$ & $49(61.25)$ & & \\
\hline Countryside & $33(33.00)$ & $31(38.75)$ & & \\
\hline Educational level & & & 0.818 & 0.366 \\
\hline$\geq$ University & $42(42.00)$ & $39(48.75)$ & & \\
\hline$<$ University & $58(58.00)$ & $41(51.25)$ & & \\
\hline FBG $(\mathrm{mmol} / \mathrm{l})$ & $5.53 \pm 1.37$ & $5.74 \pm 2.26$ & 0.769 & 0.443 \\
\hline $\mathrm{Hb}(\mathrm{g} / \mathrm{l})$ & $116.58 \pm 10.85$ & $119.57 \pm 13.53$ & 1.646 & 0.102 \\
\hline $\mathrm{RBC}\left(\mathrm{x} 10^{12} / \mathrm{l}\right)$ & $4.63 \pm 0.35$ & $4.71 \pm 0.45$ & 1.342 & 0.181 \\
\hline $\operatorname{PLT}\left(\mathrm{x} 10^{9} / 1\right)$ & $147.48 \pm 15.28$ & $151.52 \pm 16.37$ & 1.708 & 0.090 \\
\hline $\operatorname{AST}(\mathrm{U} / \mathrm{l})$ & $21.73 \pm 9.65$ & $20.45 \pm 8.65$ & 0.926 & 0.356 \\
\hline ALT (U/l) & $19.42 \pm 8.26$ & $17.35 \pm 9.41$ & 1.570 & 0.118 \\
\hline Uric acid $(\mu \mathrm{mol} / \mathrm{l})$ & $298.16 \pm 65.37$ & $281.52 \pm 45.38$ & 1.934 & 0.055 \\
\hline Serum creatinine $(\mu \mathrm{mol} / \mathrm{l})$ & $79.13 \pm 14.16$ & $75.61 \pm 12.59$ & 1.740 & 0.084 \\
\hline \multicolumn{5}{|l|}{ Cardiac function grading } \\
\hline Grade I & $20(20.00)$ & - & & \\
\hline Grade II & $26(26.00)$ & - & & \\
\hline Grade III & $30(30.00)$ & - & & \\
\hline Grade IV & $24(24.00)$ & - & & \\
\hline
\end{tabular}

FBG, fasting blood glucose; Hb, hemoglobin; RBC, red blood cell count; PLT, platelet count; AST, aspartate aminotransferase; ALT, alanine aminotransferase.

count, aspartate aminotransferase (AST), alanine aminotransferase (ALT), uric acid or serum creatinine $(\mathrm{P}>0.05)$ (Table I).

Comparison of Gal-3 concentration. In group A, Gal-3 concentration was $7.16 \pm 1.63 \mathrm{ng} / \mathrm{ml}$ before treatment and $4.37 \pm 1.52 \mathrm{ng} / \mathrm{ml}$ after treatment. The concentration was $3.26 \pm 1.43 \mathrm{ng} / \mathrm{ml}$ in group B. Gal-3 concentration in group A was significantly higher than that in group $\mathrm{B}(\mathrm{P}<0.05)$. After treatment, the concentration in group A was significantly lower than that before treatment $(\mathrm{P}<0.05)$, but significantly higher than that in group $\mathrm{B}(\mathrm{P}<0.05)$ (Fig. 1).

Correlation of Gal-3 concentration with cardiac function grading in group A. Gal-3 concentration was significantly higher in patients with cardiac function grades II, III and IV than that in patients with grade $\mathrm{I}(\mathrm{P}<0.05)$. The concentration increased with the rise of cardiac function grading. Cardiac function grade I was set as 1 , grade II as 2, grade III as 3 and grade IV as 4. According to Spearman's correlation, Gal-3 concentration was positively correlated with cardiac function grading $(\mathrm{r}=0.569, \mathrm{P}<0.001)$ (Table II and Fig. 2).

Comparison of diastolic function indexes. Compared with before treatment in group A, patients after treatment had significantly higher EPFV and EPFV/APFV $(\mathrm{P}<0.05)$, but significantly lower APFV and E/E' $(\mathrm{P}<0.05)$. Compared with group $\mathrm{B}$, patients in group A after treatment had significantly lower EPFV and EPFV/APFV $(\mathrm{P}<0.05)$, but significantly higher APFV and $\mathrm{E} / \mathrm{E}^{\prime}(\mathrm{P}<0.05)$ (Table III).

Gal-3 concentration before treatment in the effective and invalid groups and its predictive value for efficacy. During treatment, group A had 2 patients with nausea and 1 patient with dizziness, none of whom were treated. After treatment, 
Table II. Correlation of Gal-3 concentration with cardiac function grading in group $\mathrm{A}$ (mean $\pm \mathrm{SD})$.

\begin{tabular}{lcc}
\hline Cardiac function grading & $\mathrm{n}$ & Gal-3 $(\mathrm{ng} / \mathrm{ml})$ \\
\hline Grade I & 20 & $4.63 \pm 0.89$ \\
Grade II & 26 & $6.74 \pm 1.43^{\mathrm{a}}$ \\
Grade III & 30 & $7.89 \pm 1.76^{\mathrm{a}, \mathrm{b}}$ \\
Grade IV & 24 & $8.37 \pm 2.26^{\mathrm{a}-\mathrm{c}}$ \\
F-value & - & 21.370 \\
P-value & - & $<0.001$ \\
\hline
\end{tabular}

${ }^{\mathrm{a}} \mathrm{P}<0.05$, compared with grade I; ${ }^{\mathrm{b}} \mathrm{P}<0.05$ compared with grade II; ${ }^{\mathrm{c}} \mathrm{P}<0.05$, compared with grade III. Gal-3, galectin-3.

Table III. Comparison of diastolic function indexes before and after treatment in group A, and between group A and group B $($ mean $\pm \mathrm{SD})$.

\begin{tabular}{lrrr}
\hline & \multicolumn{2}{c}{ Group A $(\mathrm{n}=100)$} & \\
\cline { 2 - 3 } & $\begin{array}{c}\text { Before } \\
\text { treatment }\end{array}$ & $\begin{array}{c}\text { After } \\
\text { treatment }\end{array}$ & $\begin{array}{c}\text { Group B } \\
(\mathrm{n}=80)\end{array}$ \\
\hline EPFV (m/sec) & $0.67 \pm 0.13$ & $0.76 \pm 0.17^{\mathrm{a}}$ & $0.81 \pm 0.14^{\mathrm{a}, \mathrm{b}}$ \\
$\mathrm{APFV}(\mathrm{m} / \mathrm{sec})$ & $0.81 \pm 0.15$ & $0.72 \pm 0.14^{\mathrm{a}}$ & $0.63 \pm 0.12^{\mathrm{a}, \mathrm{b}}$ \\
$\mathrm{EPFV} / \mathrm{APFV}$ & $0.84 \pm 0.13$ & $1.03 \pm 0.16^{\mathrm{a}}$ & $1.22 \pm 0.16^{\mathrm{a}, \mathrm{b}}$ \\
$\mathrm{E} / \mathrm{E}^{\prime}$ & $17.24 \pm 4.57$ & $13.42 \pm 3.18^{\mathrm{a}}$ & $7.86 \pm 2.54^{\mathrm{a}, \mathrm{b}}$ \\
\hline
\end{tabular}

${ }^{\mathrm{a}} \mathrm{P}<0.05$, compared with the same index before treatment; ${ }^{\mathrm{b}} \mathrm{P}<0.05$, compared with the same index after treatment. Gal-3, galectin-3; EPFV, early peak flow velocity; APFV, atrial peak flow velocity; EPFV/APFV, maximum flow velocity ratio of early to atrial diastole; $\mathrm{E} / \mathrm{E}^{\prime}$, peak mitral annulus velocity.

group A had 39 markedly effective patients, 32 effective patients and 29 invalid patients. According to efficacy after treatment, the patients in group A were divided into the effective group (71 patients) and the invalid group (29 patients). Before treatment, Gal-3 concentration in the effective group was $6.41 \pm 1.73 \mathrm{ng} / \mathrm{ml}$, significantly lower than $9.16 \pm 2.37 \mathrm{ng} / \mathrm{ml}$ in the invalid group $(\mathrm{P}<0.05)$. The ROC curve of Gal-3 concentration before treatment was plotted for diagnosing the efficacy for hypertension complicated with diastolic dysfunction. The AUC of Gal-3 concentration was 0.792 (95\% CI, 0.691-0.894), the sensitivity was $73.24 \%$ and the specificity was $79.31 \%$, with an optimal cut-off value of $7.68 \mathrm{ng} / \mathrm{ml}$ (Table IV and Fig. 3).

\section{Discussion}

With an increasing incidence in recent years, hypertension is an important risk factor for many cardiovascular diseases (15). Major cardiac changes in patients with hypertension are left ventricular enlargement and hypertrophy, which are leading causes of cardiac diastolic dysfunction (16). In the early stage of cardiac diastolic dysfunction, the symptoms and signs of heart failure are unapparent. However, as the disease

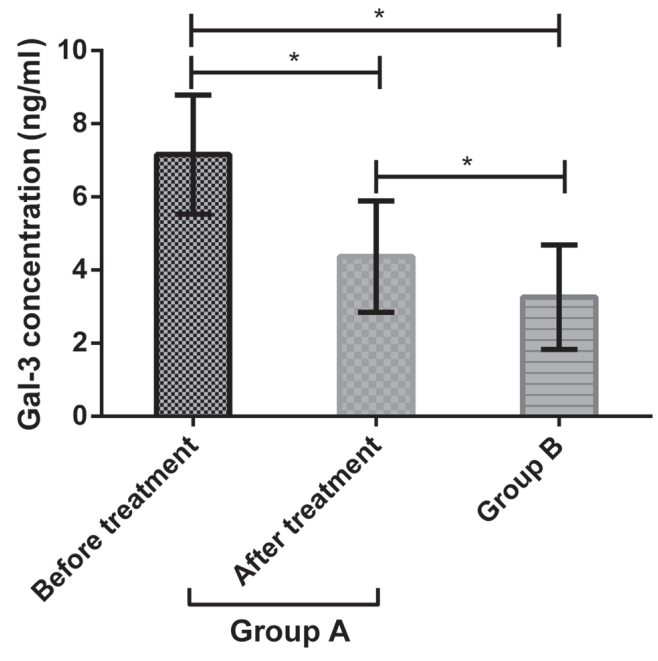

Figure 1. Comparison of serum Gal-3 concentration before and after treatment between group A and group B. According to ELISA, serum Gal-3 concentration in group A was significantly higher than that in group B $(\mathrm{P}<0.05)$. After treatment, the concentration in group A was significantly lower than that before treatment $(\mathrm{P}<0.05)$, but significantly higher than that in group $\mathrm{B}(\mathrm{P}<0.05)$. ${ }^{*} \mathrm{P}<0.05$. Gal-3, galectin-3; ELISA, enzyme-linked immunosorbent assay.

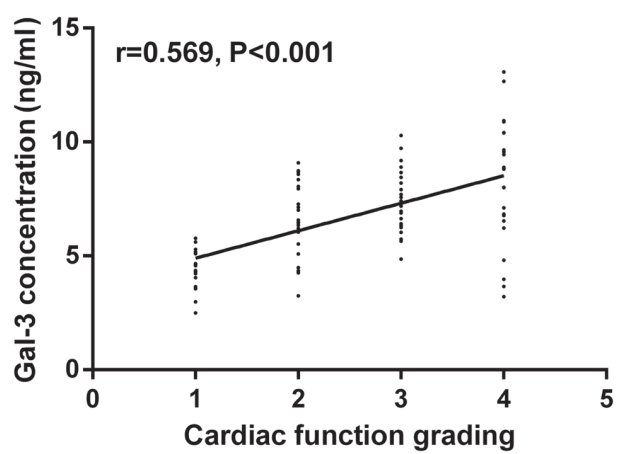

Figure 2. Correlation of serum Gal-3 concentration with cardiac function grading in group A. Serum Gal-3 concentration was positively correlated with cardiac function grading $(\mathrm{r}=0.569, \mathrm{P}<0.001)$. Gal-3, galectin-3.

progresses, most patients with cardiac diastolic dysfunction suffer from secondary systolic dysfunction, aggravated signs and symptoms of heart failure (17). Therefore, it is particularly important to find biomarkers related to the development, progression and treatment of hypertension complicated with diastolic dysfunction.

As a $\beta$-galactoside-binding lectin and a member of the soluble protein family, Gal-3 present in the nucleus promotes vascular injury and cardiovascular fibrosis. In patients with heart failure, plasma Gal-3 level has been proven to be the best predictor of short-term prognosis (18). There are many studies on Gal-3 in hypertension and heart failure. According to Calvier et al (19), Gal-3 concentration in plasma of patients with pulmonary hypertension significantly increases, so Gal-3 plays an important role in the pathophysiological process of the disease, and it can be used as a biomarker for reflecting the functional state and disease progression of the disease. According to Singh et al (20), Gal-3 is involved in the pathogenesis of cardiac fibrosis which is a leading cause of diastolic dysfunction, so it can be used as a predictor of diastolic 
Table IV. ROC curve analysis of serum Gal-3 concentration predicting the therapeutic effect of hypertension combined with diastolic dysfunction.

\begin{tabular}{lcccccc}
\hline Diagnostic indicator & AUC & $95 \%$ CI & Std. Error & Cut-off & Sensitivity (\%) & Specificity (\%) \\
\hline Gal-3 (ng/ml) & 0.792 & $0.691-0.894$ & 0.052 & 7.68 & 73.24 & 79.31 \\
\hline
\end{tabular}

ROC, receiver operating characteristic; Gal-3, galectin-3; AUC, area under curve; CI, confidence interval.
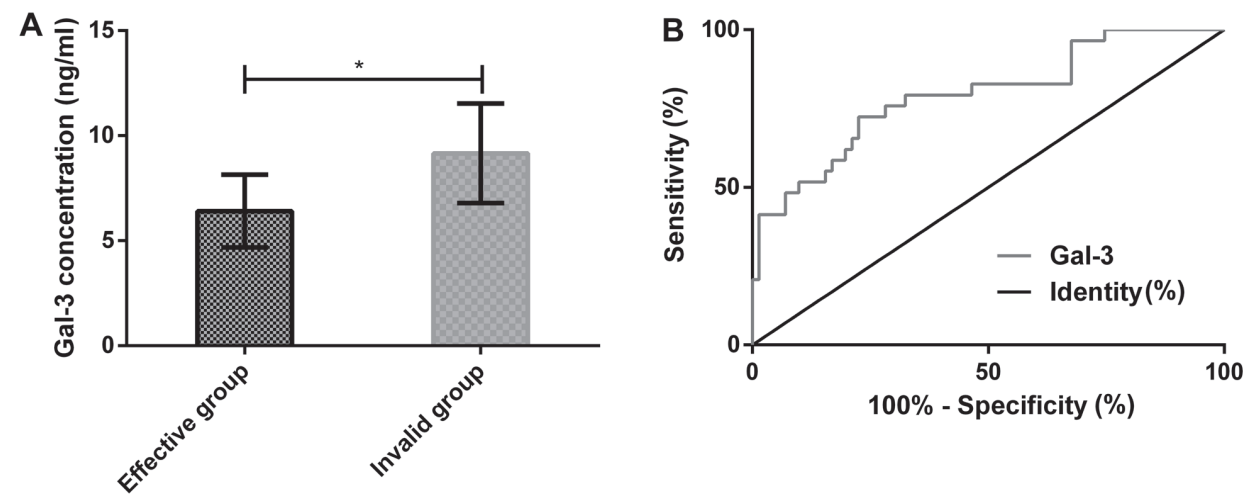

Figure 3. Serum Gal-3 concentration before treatment in the effective and invalid groups and its predictive value for efficacy. (A) According to ELISA, before treatment, serum Gal-3 concentration in the effective group was significantly lower than that in the invalid group $(\mathrm{P}<0.05)$. (B) According to the ROC curve, the AUC of serum Gal-3 concentration for evaluating efficacy was 0.792 (95\% CI, 0.691-0.894), the sensitivity was $73.24 \%$ and the specificity was $79.31 \%$, with an optimal cut-off value of $7.68 \mathrm{ng} / \mathrm{ml}$. ${ }^{*} \mathrm{P}<0.05$. Gal-3, galectin-3; ELISA, enzyme-linked immunosorbent assay; AUC, area under curve; ROC, receiver operating characteristic.

dysfunction in patients with atrial fibrillation and heart failure. The results of this study showed that Gal-3 concentration in group A was significantly higher than that in group B, and positively correlated with cardiac function grading; that is, Gal-3 concentration significantly increased with the rise of cardiac function grading. These findings indicate that Gal-3 may be involved in the development and progression of hypertension complicated with diastolic dysfunction, and it increases with the aggravation of the disease. This is similar to the findings of previous studies. The pathological process of hypertensive disease progression is myocardial fibrosis (21). Therefore, Gal-3 as a marker for myocardial fibrosis (22) may gradually increase with the deterioration of cardiac function and the aggravation of myocardial fibrosis.

Clinically, patients with hypertension are commonly treated with ACEI, ARB, CCB and $\beta$-receptor blockers, which can control blood pressure, improve cardiac structure and function, and inhibit myocardial fibrosis and the release of inflammatory cytokines. They can also reduce the left ventricle and its cardiac chamber, and improve cardiac diastolic function (23-26). In the present study, after treatment, Gal-3 concentration in group A was significantly lower than that before treatment, but significantly higher than that in group B. Although the patients' Gal-3 concentration after treatment did not return to normal, their cardiac diastolic function was improved. Therefore, the inhibition of Gal-3 concentration may be one of the therapeutic mechanisms. In a study by Calvier et al (27), the increasing expression of Gal-3 in experimental hyperaldosteronism is related to cardiac and renal fibrosis and dysfunction. Inhibition or blocking of the expression through drugs reduces cardiac and renal fibrosis, so Gal-3 can be used as a new target for pharmacological intervention. According to a study by Vergaro et al (28), the inhibition of Gal-3 expression and protein content prevents isoproterenol-induced left ventricular dysfunction and fibrosis in mice. Therefore, Gal-3 concentration may affect the treatment of the disease. In this study, before treatment, Gal-3 concentration in the effective group was significantly lower than that in the invalid group. According to the ROC curve, Gal-3 concentration before treatment had a high diagnostic value for the clinical efficacy. These findings indicate that Gal-3 concentration before treatment has a predictive value for efficacy.

This study confirmed the role of Gal-3 concentration in the development, progression and treatment of patients with hypertension complicated with diastolic dysfunction, but it still has deficiencies in design. Drugs were given based on the patients' signs and symptoms, so their specific effects on Gal-3 concentration remain unclear and risk factors affecting the onset and treatment of the disease were not explored. These deficiencies require further research to support the results of this study.

In conclusion, Gal-3 may be involved in the development and progression of hypertension complicated with diastolic dysfunction. Its concentration increases with the rise of cardiac function grading but significantly decreases after treatment. Therefore, Gal-3 concentration before treatment can be used as a potential predictor of efficacy.

\section{Acknowledgements}

Not applicable. 


\section{Funding}

This study was supported by Heilongjiang Provincial Health and Family Planning Commission Research Project 2017-381.

\section{Availability of data and materials}

The datasets used and/or analyzed during the present study are available from the corresponding author on reasonable request.

\section{Authors' contributions}

TD and HL conceived and designed the study. TD, HL, SW and WC were responsible for the collection and analysis of the experimental data. HL and WC interpreted the data and drafted the manuscript. TD revised the manuscript critically for important intellectual content. All authors read and approved the final manuscript.

\section{Ethics approval and consent to participate}

The study was approved by the Ethics Committee of The First Affiliated Hospital of Jiamusi University (Jiamusi, China). Signed informed consents were obtained from the patients or the guardians.

\section{Patient consent for publication}

Not applicable.

\section{Competing interests}

The authors declare that they have no competing interests.

\section{References}

1. Leung AA, Nerenberg K, Daskalopoulou SS, McBrien K, Zarnke KB, Dasgupta K, Cloutier L, Gelfer M, LamarreCliche M, Milot A, et al; CHEP Guidelines Task Force: Hypertension Canada's 2016 Canadian hypertension education program guidelines for blood pressure measurement, diagnosis, assessment of risk, prevention, and treatment of hypertension. Can J Cardiol 32: 569-588, 2016.

2. Oluboka OJ, Katzman MA, Habert J, McIntosh D, MacQueen GM, Milev RV, McIntyre RS and Blier P: Functional recovery in major depressive disorder: Providing early optimal treatment for the individual patient. Int J Neuropsychopharmacol 21: 128-144, 2018 ,

3. Soullier C, Niamkey JT, Ricci JE, Messner-Pellenc P, Brunet X and Schuster I: Hypertensive patients with left ventricular hypertrophy have global left atrial dysfunction and impaired atrio-ventricular coupling. J Hypertens 34: 1615-1620, 2016.

4. Ravassa S, López B, Querejeta R, Echegaray K, San José G, Moreno MU, Beaumont FJ, González A and Díez J: Phenotyping of myocardial fibrosis in hypertensive patients with heart failure. Influence on clinical outcome. J Hypertens 35: 853-861, 2017.

5. Nazário Leão R and Marques da Silva P: Diastolic dysfunction in hypertension. Hipertens Riesgo Vasc 34: 128-139, 2017.

6. Ginelli $\mathrm{P}$ and Bella JN: Treatment of diastolic dysfunction in hypertension. Nutr Metab Cardiovasc Dis 22: 613-618, 2012.

7. Nadruz W, Shah AM and Solomon SD: Diastolic dysfunction and hypertension. Med Clin North Am 101: 7-17, 2017.

8. Zhang Y, Sun N, Jiang X and Xi Y: Comparative efficacy of $\beta$-blockers on mortality and cardiovascular outcomes in patients with hypertension: A systematic review and network meta-analysis. J Am Soc Hypertens 11: 394-401, 2017.

9. Wallentin F, Wettermark B and Kahan T: Drug treatment of hypertension in Sweden in relation to sex, age, and comorbidity. J Clin Hypertens (Greenwich) 20: 106-114, 2018.
10. Anyfanti P, Gkaliagkousi E, Gavriilaki E, Triantafyllou A, Dolgyras P, Galanopoulou V, Aslanidis S and Douma S: Association of galectin-3 with markers of myocardial function, atherosclerosis, and vascular fibrosis in patients with rheumatoid arthritis. Clin Cardiol 42: 62-68, 2019.

11. González GE, Rhaleb NE, D'Ambrosio MA, Nakagawa P, Liao TD, Peterson EL, Leung P, Dai X, Janic B, Liu YH, et al: Cardiac-deleterious role of galectin-3 in chronic angiotensin II-induced hypertension. Am J Physiol Heart Circ Physiol 311: H1287-H1296, 2016.

12. Jagodzinski A,Havulinna AS, Appelbaum S,Zeller T, Jousilahti P, Skytte-Johanssen S, Hughes MF, Blankenberg S and Salomaa V: Predictive value of galectin-3 for incident cardiovascular disease and heart failure in the population-based FINRISK 1997 cohort. Int J Cardiol 192: 33-39, 2015.

13. Meijers WC, van der Velde AR and de Boer RA: ST2 and galectin-3: Ready for prime time? EJIFCC 27: 238-252, 2016.

14. Ghorpade AG, Shrivastava SR, Kar SS, Sarkar S, Majgi SM and Roy G: Estimation of the cardiovascular risk using World Health Organization/International Society of Hypertension (WHO/ISH) risk prediction charts in a rural population of South India. Int J Health Policy Manag 4: 531-536, 2015.

15. Wang Z, Chen Z, Zhang L, Wang X, Hao G, Zhang Z, Shao L, Tian Y, Dong Y, Zheng C, et al; China hypertension survey investigators: Status of hypertension in China: Results from the China hypertension survey, 2012-2015. Circulation 137: 2344-2356, 2018.

16. Bansal M, Kasliwal RR and Trehan N: Relationship between different cardiovascular risk scores and measures of subclinical atherosclerosis in an Indian population. Indian Heart J 67: 332-340, 2015.

17. Deckx S, Heggermont W, Carai P, Rienks M, Dresselaers T, Himmelreich U, van Leeuwen R, Lommen W, van der Velden J, Gonzalez A, et al: Osteoglycin prevents the development of age-related diastolic dysfunction during pressure overload by reducing cardiac fibrosis and inflammation. Matrix Biol 66: 110-124, 2018.

18. Maiolino G, Rossitto G,Pedon L, Cesari M,Frigo AC, Azzolini M, Plebani M and Rossi GP: Galectin-3 predicts long-term cardiovascular death in high-risk patients with coronary artery disease. Arterioscler Thromb Vasc Biol 35: 725-732, 2015.

19. Calvier L, LegchenkoE, Grimm L, Sallmon H, Hatch A,Plouffe BD, Schroeder C, Bauersachs J, Murthy SK and Hansmann G: Galectin-3 and aldosterone as potential tandem biomarkers in pulmonary arterial hypertension. Heart 102: 390-396, 2016.

20. Singh T, Pilania M, Jat GS and Kumar R: Ambiguity about selection of cardiovascular risk stratification tools: Evidence from a North Indian rural population. Indian J Community Med 43: 170-174, 2018.

21. Wu H, Chen L, Xie J, Li R, Li GN, Chen QH, Zhang XL, Kang LN and Xu B: Periostin expression induced by oxidative stress contributes to myocardial fibrosis in a rat model of high salt-induced hypertension. Mol Med Rep 14: 776-782, 2016.

22. Hogas S, Bilha SC, Branisteanu D, Hogas M, Gaipov A, Kanbay M and Covic A: Potential novel biomarkers of cardiovascular dysfunction and disease: Cardiotrophin-1, adipokines and galectin-3. Arch Med Sci 13: 897-913, 2017.

23. Gorostidi $\mathrm{M}$ and de la Sierra A: Combination therapy in hypertension. Adv Ther 30: 320-336, 2013.

24. Shah SJ and Stafford RS: Current trends of hypertension treatment in the United States. Am J Hypertens 30: 1008-1014, 2017.

25. Taddei S: Combination therapy in hypertension: What are the best options according to clinical pharmacology principles and controlled clinical trial evidence? Am J Cardiovasc Drugs 15: 185-194, 2015.

26. Gradman AH: Strategies for combination therapy in hypertension. Curr Opin Nephrol Hypertens 21: 486-491, 2012.

27. Calvier L, Martinez-Martinez E, Miana M, Cachofeiro V, RousseauE,Sádaba JR,ZannadF, Rossignol P and López-Andrés N: The impact of galectin-3 inhibition on aldosterone-induced cardiac and renal injuries. JACC Heart Fail 3: 59-67, 2015.

28. Vergaro G, Prud'homme M, Fazal L, Merval R, Passino C, Emdin M, Samuel JL, Cohen Solal A and Delcayre C: Inhibition of galectin-3 pathway prevents isoproterenol-induced left ventricular dysfunction and fibrosis in mice. Hypertension 67: 606-612, 2016. International (CC BY-NC-ND 4.0) License. 